\title{
Perspectiva de las personas menores de edad acerca de la violencia en los medios de comunicación: videojuegos, televisión y música
}

\section{Children's View of Violence in the Media: Video Games, Television and Music}

\author{
Marianella Castro Pérez' \\ Instituto de Estudios Interdisciplinarios de la Niñez y Adolescencia (INEINA) \\ Universidad Nacional \\ Heredia, Costa Rica \\ nella_cp@yahoo.com
}

María Ester Morales Ramírez ${ }^{2}$

Instituto de Estudios Interdisciplinarios de la Niñez y Adolescencia (INEINA)

Universidad Nacional

Heredia, Costa Rica

mmorales@una.ac

Recibido 15 de abril de 2013 • Corregido 27 de junio de 2013 • Aceptado 31 de julio de 2013

\begin{abstract}
Resumen. El presente artículo científico tiene como propósito generar la autorreflexión y concienciación del rol que desempeñan las personas adultas ante la problemática de la violencia y los factores protectores y de riesgo asociados a esta, con el fin de ser propositivos en aras de garantizarles un desarrollo integral en contextos que promuevan el derecho a la paz. La investigación fue de tipo descriptiva y explicativa con un enfoque mixto (cualitativo y cuantitativo). El estudio se realizó con 390 estudiantes en centros educativos de primaria y secundaria de todas las provincias del país, excepto Guanacaste. Para la recolección de los datos, se diseñaron dos cuestionarios con preguntas abiertas y cerradas, dirigidos al estudiantado participante. A partir de las respuestas brindadas por las personas participantes, se procedió a elaborar los manuales de categorías y, eventualmente, las tablas, descripciones y análisis de los datos. Se estima que el aporte del artículo permitirá la búsqueda de soluciones y alternativas para que quienes trabajan directa o indirectamente con personas menores de edad, puedan enfrentar asertivamente la violencia y brindarles oportunidades para lograr una vida de calidad y una convivencia pacífica en sociedad.
\end{abstract}

Palabras claves. Violencia, videojuegos, televisión, música, niños, niñas, adolescentes, derecho, paz.

$1 \quad$ Máster en Administración Educativa. Licenciada en Educación Preescolar. Académica en el Instituto de Estudios Interdisciplinarios de la Niñez y Adolescencia (INEINA) y de la División de Educación Básica del Centro de Investigación y Docencia en Educación de la Universidad Nacional de Costa Rica.

2 Doctora en Educación con Énfasis en Investigación Educativa. Máster en Psicología Industrial y Organizacional. Licenciada en Psicología. Académica en el Instituto de Estudios Interdisciplinarios de la Niñez y Adolescencia (INEINA) del Centro de Investigación y Docencia en Educación de la Universidad Nacional de Costa Rica. 
URL: http://www.una.ac.cr/educare

CORREO: educare@una.cr

\begin{abstract}
The purpose of this research article is to generate awareness and self-analysis regarding the role played by adults with respect to violence in the media and the risk and protective factors associated with it, in order to propose a proactive approach that ensures children and adolescents a comprehensive development in environments that promote the right to peace. The research was descriptive and explanatory with a mixed approach (qualitative and quantitative). The study was conducted with 390 students (from $1^{\text {st }}$ to $11^{\text {th }}$ grades) in all provinces of Costa Rica, except Guanacaste. For data collection, two questionnaires with open and closed questions were designed and applied to the students. Based on the answers provided by the participants, the researchers prepared manuals of categories, tables, descriptions, and data analysis. This paper will contribute to find solutions and alternatives for those working directly or indirectly with children to be able to deal with violence in the media in a more assertive manner, giving children the opportunity of a good quality of life and a peaceful coexistence in the society.
\end{abstract}

Keywords. Violence, video games, TV, music, children, adolescents, rights, peace.

Las autoras del artículo, como parte del quehacer del Instituto de Estudios Interdisciplinarios de la Niñez y la Adolescencia, han venido investigando el fenómeno de la violencia en los diversos ámbitos en los que se desenvuelven las personas menores de edad, con miras a conocer, de manera más profunda, la problemática y plantear recomendaciones y sugerencias para su prevención y abordaje. Es en este contexto donde se gesta la investigación titulada Violencia en los diversos ámbitos: familia, comunidad, centro educativo y medios de comunicación, cuyo objetivo general fue conocer la percepción de violencia que tienen los padres, las madres, educadores, así como las niñas, niños y adolescentes de 18 centros educativos en seis provincias del país. Más específicamente, se buscó estar al tanto de los conocimientos de estos grupos de población acerca del concepto de violencia, las creencias, las diferentes formas de violencia y los factores protectores y de riesgo de la violencia utilizados por docentes en los centros educativos.

La violencia se constituye en una violación de los derechos humanos, especialmente el derecho de las personas menores de edad a la convivencia pacífica en los diversos contextos en los que se desenvuelven; por esto y dada la relevancia del tema que nos ocupa hoy día y la riqueza y amplitud de los resultados obtenidos en la investigación precitada, el presente artículo abordará solo los datos atinentes a la violencia en los medios de comunicación, a saber, la televisión, la música y los videojuegos, desde la perspectiva de las personas menores de edad. Se estima que este será un aporte significativo que permitirá la búsqueda de soluciones y alternativas viables para enfrentar la crisis que vive el país y que afecta tanto a estudiantes, como a la sociedad en general, limitándoles las oportunidades para lograr una vida de calidad.

\title{
Consideraciones teóricas
}

El problema de la violencia en la sociedad es como una espiral en la que todo parece estar interrelacionado; por eso, la influencia de los medios de comunicación es solo uno de los factores que día tras día muestran un contexto conflictivo y hostil. Al respecto, resulta imperativa la necesidad de generar autorreflexión y concienciación acerca del papel que desempeñan las 
personas adultas para romper con el ciclo tan peligroso que cada vez arrastra y destruye más víctimas a su paso.

En opinión de la Organización Panamericana de la Salud y la Organización Mundial de la Salud (2003, p. 13) la violencia es "...el resultado de la acción recíproca y compleja de factores individuales, sociales, relacionales, culturales y ambientales..." que explican los diferentes niveles que repercuten en los actos violentos.

Aunado a lo anterior, Rodríguez (citado por León, 2009) señala que los impulsos a actuar no necesariamente son negativos, lo son cuando dañan a otro individuo o a la persona misma. El conflicto puede ser constructivo, ya que si este es administrado simbólicamente permite el crecimiento de los actores sociales en pugna. Sin embargo, es destructivo cuando el conflicto de intereses se resuelve por dominio, amaestramiento o sometimiento del otro.

Agregan Ortega y Mora-Merchán (1998) que se debe distinguir entre el juego rudo y los actos de verdadera violencia. Esto, por cuanto en variadas ocasiones los niños varones tienden al juego mediante el contacto físico o de simulación de peleas, ya sea en parejas o en pequeños grupos en donde se persiguen y se agarran, se tiran al suelo en medio de algarabía y gritos; pero siempre mostrando una actitud alegre y una sonrisa. En cambio, los actos de violencia implican agresión real, dificultad para comunicarse, para relacionarse y un marcado sentimiento de desconfianza.

\section{Tipos de violencia}

Los tipos de violencia más frecuentes en los medios de comunicación, según León (2009) y la Fundación Paniamor (1998), son:

Violencia física: acción abusiva que arriesga o daña la integridad corporal de una persona, usando fuerza física o arma, que provoque o lesione.

Violencia verbal: daño a otra persona más débil e indefensa, insultándole, llamándole con motes, amenazándole, burlándose de él o ella y de sus pertenencias.

Violencia psicológica: degradación o control de las acciones, comportamiento, creencias y decisiones de otras personas; intimida, manipula, amenaza, humilla y aisla perjudicando la salud emocional.

Violencia patrimonial: daño, transformación, sustracción, retención, destrucción de objetos, documentos, bienes, derechos o recursos económicos destinados a satisfacer las necesidades de alguna de las víctimas.

Violencia sexual: exigencia a una persona para que mantenga contacto sexual -físico o verbal- mediante el uso de la fuerza, intimidación, coerción, chantaje, manipulación, amenaza que limita o elimina la voluntad de quien está siendo abusada o abusada. 
URL: http://www.una.ac.cr/educare

CORREO: educare@una.cr

Además, León (2009) opina que se observan episodios de violencia frecuentes en los contextos inmediatos en donde se desenvuelven los niños, niñas y adolescentes, tales como:

En la comunidad, el barrio o vecindario: problemas de barras o pandillas y otras dificultades en las calles y las carreteras.

En los centros educativos: manifestaciones de rechazo o agresiones abiertas relacionadas con dinámicas de la escuela y del aula, con la calidad de las relaciones interpersonales y de los vínculos que se establezcan, y con el proceso de enseñanza y aprendizaje que se ponga en práctica.

En la familia: evidencia de negligencia, castigos inapropiados, maltrato, abuso sexual, explotación laboral, explotación sexual comercial y separaciones o divorcios difíciles. La violencia en ocasiones tiene que ver con las condiciones físicas y recursos, la estructura y ambiente familiar, la dinámica de pareja, las relaciones familiares y la calidad de la atención que reciben los hijos y las hijas.

En los medios de comunicación: presente en la televisión, los videojuegos, la computadora, el internet, la música y las revistas, entre otros.

Puede derivarse de lo anterior que los ámbitos en los que se presenta la violencia cotidianamente son diversos; no obstante, para efectos del presente artículo se ha considerado oportuno referirse solo a la que se genera a partir de la influencia de los medios de comunicación: la televisión, la música y los videojuegos.

\section{La violencia en los medios de comunicación}

Cada día es más amplio el repertorio acerca de la violencia que ofrecen los medios de comunicación (televisión, televisión por satélite, cine, videos, videojuegos, música, ordenador, internet) a los niños, niñas y adolescentes. Este fenómeno ha sido estudiado debido al incremento de programas violentos que observan las personas menores de edad, a la cantidad de noticias, videos con contenidos obscenos y no aptos que circulan a diario por la Internet, a los juegos de video, la música y hasta por los diarios nacionales.

Sánchez (1998) plantea que la violencia representada en el cine, televisión, audio, impresos o interpretaciones en vivo no es necesariamente la misma violencia de la vida real, ya que los medios de comunicación pueden utilizar muchos recursos artificiales para aminorar o incrementar la gravedad de los hechos, aspectos que no son percibidos o analizados en muchas ocasiones por la población televidente, en especial en el caso de los niños, las niñas y adolescentes. 
Es indudable que los medios de comunicación ocupan un lugar determinante en la socialización, ya que se encarga de asignarles a ellos y ellas el rol que deben cumplir en su contexto social y de enseñarles cómo dirigir sus relaciones hacia una lucha de poder, pues los niños y niñas son considerados excelentes imitadores de conductas a partir de su proceso de socialización (Levine, 1997). Sin embargo, lo más lamentable es que ese rol que se les demanda, repercute negativamente en su desarrollo y bienestar como seres humanos integrales.

Agrega Levine (1997) que las escenas de violencia transmitidas por los medios de comunicación se han vuelto tan rutinarias que las personas ya no las reconocen como tales, lo cual es preocupante ya que "...cuanta más violencia veamos y cuanto menos nos perturbe, tanto mayor es el riesgo de volvernos tolerantes a la violencia en la vida real" (p. 44). Es decir, en tanto las personas se desensibilicen ante la gran variedad de formas de violencia, esta se convierte en una amenaza que puede llevar a los seres humanos a invisibilizar las consecuencias y el sufrimiento que se experimenta por su causa.

Pero no solo la televisión es considerada como un factor de riesgo que influye en las conductas, actitudes y valores de los niños, niñas y adolescentes. También la música y sus mensajes agresivos, provocativos y en algunas ocasiones hasta obscenos o satánicos, provocan que las personas menores de edad los empleen como un medio natural de comunicación, el cual imitan y ponen en práctica permanentemente en su cotidianidad.

Aunado a la influencia de la televisión y la música, este mismo autor indica que están los juegos de video y sus personajes, la mayoría de las veces desempeñando roles de monstruos, guerreros, luchadores, ladrones, asesinos, acosadores, violadores, entre otros. Estos orientan e inducen a emitir conductas matizadas por antivalores como la rivalidad, el dominio, las demostraciones de fuerza ante los otros, ya que sus mensajes giran en torno a que "se debe derribar rivales para poder avanzar", "solo se llega a la meta por medio de golpes, agresiones y eliminación de los enemigos" y finalmente "matar para ganar" y de esta manera obtener lo que se desea (Levine, 1997, p. 44). Esto es especialmente preocupante, por cuanto conlleva a la distorsión del concepto de juego como una herramienta socializadora que favorece el aprendizaje y el desarrollo integral.

Asimismo, se ha relacionado la influencia de los medios de comunicación con el consumo de bebidas alcohólicas, cigarrillos, el inicio temprano de la actividad sexual y con la omisión de medidas anticonceptivas, por lo tanto, cabría pensar que es un factor de alto riesgo dentro del fenómeno de la violencia y las consecuencias que esta genera.

Cabe mencionar que toda actividad de los medios de comunicación está regulada en la Ley general de espectáculos públicos, materiales audiovisuales e impresos Ley no. 7440 (1999), normativa que es clara al señalar en su Artículo 1 que "el Estado debe ejercer para proteger a la sociedad, particularmente a los menores de edad y a la familia, en cuanto al acceso a los espectáculos públicos, a los materiales audiovisuales e impresos ..." y en su Artículo 3 la "ley regula la valoración de los contenidos de las siguientes actividades: a) espectáculos públicos, particularmente el cine y las presentaciones en vivo, b) radio, c) televisión por VHF, UHF, cable, 
URL: http://www.una.ac.cr/educare

CORREO: educare@una.cr

medios inalámbricos, vía satélite o cualquiera otras formas de transmisión, d) juegos de vídeo, e) alquiler de películas para video, f) material de carácter pornográfico" (p. 1).

Aunado a lo anterior, se hace referencia a que una de las funciones de la Comisión de control y calificación de espectáculos públicos es regular el ". . . contenido estrictamente pornográfico o violento, por su potencial de incitación al crimen o al vicio o por degradar la condición del ser humano" (Ley general de espectáculos públicos, materiales audiovisuales e impresos, ley no. 7440 ..., 1999, p. 3).

\section{Violencia y videojuegos}

Según Connecticut Clearinghouse. A Program of Wheeler Clinic (s. f.), un videojuego es todo aquel programa informático para el entretenimiento y que puede ser utilizado en un ordenador, una consola, un teléfono móvil o la red de Internet.

Son muchos los sectores que se han preocupado en determinar la concordancia existente entre los videojuegos y la violencia, especialmente porque la mayoría de los juegos más populares tienen un contenido violento que hace pensar están relacionados con los reiterados episodios de violencia protagonizados por las personas menores de edad. Al respecto, Tisseron (2006) considera que los videojuegos violentos guardan una estrecha reciprocidad con el comportamiento agresivo, la violencia, el aumento de los pensamientos agresivos, el aislamiento social y podría aumentar el riesgo de sufrir ataques epilépticos. Agrega que si bien existe una dependencia entre la práctica de los videojuegos violentos y la conducta agresiva, cabe preguntarse si, efectivamente, los videojuegos generan violencia o, por el contrario, son las personas violentas las que experimentan una gran atracción por los videojuegos de contenidos violentos.

Asimismo, apunta que los videojuegos impactan positivamente en los siguientes aspectos: en el área intelectual debido a que han ido perfeccionando el atractivo visual y la capacidad pedagógica, a tal grado que algunos centros educativos los emplean para enseñar ciertas materias y educar en valores, con lo cual se eleva el espíritu de superación y de adquisición de habilidades manuales. De igual manera, si son bien utilizados, son un buen recurso para el ocio, porque permiten desarrollar diversas habilidades propias del mundo digital y estimulan la actividad física, la creatividad, la imaginación, el razonamiento, la orientación espacial, la capacidad de atención, la concentración, la toma de decisiones, la expresión y el compartir sentimientos y emociones a veces reprimidos. Considera, además, que desarrolla el lenguaje e incorpora símbolos y técnicas para resolver situaciones, promoviendo, con ello, el aprendizaje en la solución de problemas, conflictos, el desarrollo de destrezas motoras y la coordinación visomotora. Finalmente se dice que fortalece el sentido de logro, autoestima y el reconocimiento social por parte de los amigos.

Tisseron (2006) menciona que el efecto negativo de los videojuegos no está vinculado a los juegos mismos, sino al aprendizaje que ha tenido el niño o niña en su entorno para resolver las situaciones conflictivas. Luego de hacer esta aclaración, este autor señala que algunos de 
los efectos negativos correlacionados con los videojuegos consisten en que la mayoría de los problemas se solucionan haciendo uso de la violencia; se dedica un tiempo desproporcionado a jugar en detrimento de otras actividades; se presenta una tendencia a mostrar una conducta más agresiva, impulsiva y egoísta y una desensibilización hacia los actos violentos; podría experimentarse síntomas de fobia social, ansiedad y sentimientos hostiles; se reciben mensajes acerca de cómo matar a las personas o animales y el uso y abuso de drogas y alcohol; se fomenta el comportamiento criminal, la falta de respeto por la autoridad y las leyes; se evidencia la explotación sexual, la violencia hacia la mujer, los estereotipos raciales, sexuales y de género y el uso de palabras indecentes y gestos obscenos. Por otra parte, anota que modifica los valores, es decir, los videojuegos, sobre todo los más violentos, podrían mostrar unos valores que no son los que se desea transmitir a las personas menores de edad. Esto afecta la relación con la familia, porque el que pasen horas jugando con los videojuegos disminuye el tiempo para estar con sus padres, es decir, pueden provocar que la persona se aleje de lo que sucede a su alrededor y tienda a encerrarse en sí misma. A su vez, se dice que los videojuegos podrían causar sobre estimulación, que a su vez lograría afectar el sistema nervioso, provocando nerviosismo e irritabilidad.

Al respecto Huerta (2005, p. 188) plantea que “. . . las videosalas son uno de los lugares de socialización dinámica de los jóvenes en los cuales interactúan e intercambian situaciones y formas de vida, concepciones, creencias y prácticas de lo que son y deben ser los hombres...", todo a partir de la experiencia del juego. Por ello, las estrategias con los oponentes reales o virtuales son simbolizadas por representaciones violentas reflejadas en las actitudes, los comportamientos, el trato y los discursos empleados por los niños, las niñas y adolescentes en su proceso de socialización.

Para este autor, jugar videojuegos violentos, y asumir y poner en práctica la violencia que observan es responsabilidad de cada persona y no de los videos, pues todo lo que ocurre en ellos no es real. Sin embargo, anota que, si bien es cierto, las personas menores de edad están conscientes de que la violencia ocurre solo en el mundo virtual de los juegos y no el real; cabe señalar que desde la perspectiva de este autor ". . . la violencia es una de las prácticas aprendidas más internalizas, normalizadas y naturalizadas de la condición genérica de los hombres..." (Huerta, 2005, p. 200), de ahí que se piense que los videos son pedagógicos en lo que al aprendizaje de la violencia se refiere. Agrega que la violencia real y virtual practicada por los hombres contra las mujeres, las niñas, los niños, las ancianas, los ancianos, contra otros hombres o hacia la naturaleza “... enajena la condición genérica y sociocultural de los hombres” (Huerta, 2005, p. 201).

En esta misma línea, Tisseron (2006) refiere que los videojuegos se han constituido en los preferidos a la hora de jugar, desplazando otros juegos recreativos y los juguetes, por lo que, en opinión de Lazo (mencionado por Tisseron, 2006), se necesita la intervención de la familia, los maestros, profesores y todas aquellas personas que forman parte del mundo del joven para decidir los contenidos que las personas menores de edad van a mirar. 
URL: http://www.una.ac.cr/educare

CORREO: educare@una.cr

Agrega Tisseron (2006) que “. .. prohibir determinados espectáculos a los menores es ...., un importante elemento de la política de protección contra los peligros de las imágenes y tiene consecuencias muy beneficiosas para la vida familiar" (p. 64) y que acompañar a los niños, niñas y adolescentes frente a la pantalla no es una opción, sino un deber que deben asumir los padres y madres de familia, pues los medios de comunicación bombardean e incitan a que ellos y ellas, desde muy pequeños, se inserten en el mundo de las imágenes que perciben por la televisión, el periódico, el cine, internet o los videojuegos, entre otros. Resalta la responsabilidad de los padres y madres de establecer, con sus hijos e hijas, la diferencia entre la ficción y la realidad, de manera que se les facilite entender que lo que miran en la televisión, cine, internet o videojuegos es diferente de lo que acontece en el mundo real.

\section{La televisión como agente socializador}

La televisión es el primer medio de comunicación utilizado para llenar el tiempo libre. En la mayoría de los hogares se enciende el televisor al llegar a casa, aún cuando la programación que se transmite no sea de interés. Es de esta manera como el rol que se le asigna a la televisión es tan transcendental que organiza la vida familiar, forma parte de la decoración, acompaña en la comida familiar, determina la hora de ir a dormir y está presente en otras festividades como la cena de Navidad o en la celebración del fin de año, entre otros.

En opinión de Leiva (s. f.), la televisión la mayoría de las veces sustituye el rol de la familia, ya que los padres le delegan sus funciones formativas; organiza el tiempo; le indica al niño quién es; le muestra lo bueno y lo malo; establece la escala de valores que debe poner en práctica; incide en el papel de los amigos; proporciona juegos, modelos y determinados roles sociales, y promueve la pérdida del lenguaje familiar, cambiándolo por otro mediocre, pobre, reiterativo, uniforme y despersonalizado.

De acuerdo con Huerta (2005), la influencia de la televisión es alarmante, no por la incidencia que tiene sobre los adultos, sino por la influencia significativa en los niños, las niñas y adolescentes, quienes aún no tienen la capacidad de decidir por sí mismos.

Añade que los miembros de las familias ya casi no conversan entre sí porque la televisión absorbe todo el tiempo, se constituye en parte de la vida cotidiana y en uno de los agentes de socialización más significativos. La televisión utiliza un lenguaje accesible, su comprensión no requiere esfuerzo ni habilidades especiales y podría llegar a ser un excelente medio educativo mediante la observación de modelos y comportamientos.

Agrega que la exposición a la televisión incrementa las acciones agresivas con extraños, compañeros de clase, amigos, independientemente de la edad, aunque afecta más a los niños preescolares, pues pasan el mayor tiempo viendo este medio de comunicación.

Tuyaret (2009) plantea que mirar la televisión sin un análisis crítico podría conllevar a creer en las manipulaciones que colocan a la persona en una posición frágil, individualista e incapaz 
de renunciar a nada. De esta manera, la indiferencia, el desprecio, el odio, la discriminación y el crimen han reemplazado valores que antes se ponían en práctica, como el amor entre los padres y los hijos, la amistad, la fidelidad, el respeto mutuo, la valentía, el coraje y la responsabilidad, entre otros.

Refiere la autora que poco a poco la televisión ha ocupado el rol del padre y la madre, en la medida que transmite, a las personas menores de edad, los modelos que deben imitar y les da todas las herramientas para su posterior inserción en la sociedad.

Huerta (2005); Lanza (2010); Leiva (s. f.) y Redondo (s. f.a) sugieren que la exposición reiterada a los programas televisivos tiene un impacto tanto positivo como negativo en las personas menores. Las ventajas que se señalan son : estimula la capacidad de aprendizaje y acceso a la información; aporta los conocimientos culturales; enriquece el lenguaje oral y el léxico; promueve ciertos comportamientos sociales; favorece el rendimiento cognitivo; promueve el juicio crítico; desarrolla las capacidades visual y sonora; estimula la curiosidad, fantasía e imaginación; entretiene y es un descanso barato; sirve de compañía a personas que están solas; posibilita el acceso a enciclopedias, bibliotecas y otros materiales informativos, y suscita el almacenamiento de conocimientos.

Los autores antes mencionados comentan que los efectos negativos corresponden a que la televisión puede provocar aislamiento familiar en la medida que cada uno mira la televisión en su cuarto, esto provoca una especie de ruptura, que si bien reduce los conflictos, sí conlleva a una mayor soledad de cada uno de los miembros de la familia; presenta una carga elevada de violencia y erotismo; incita a conductas agresivas; disminuye el tiempo dedicado a la lectura y a otras actividades; aumenta el sedentarismo y el sobrepeso; afecta la comunicación personal y bloquea la facultad de pensar; produce pasividad e irrealidad, fomentando indiferencia ante los problemas reales; favorece el culto al dinero, sexo, vida frívola y deseo del poder; fomenta el consumismo, ofreciendo productos inalcanzables; refuerza la agresividad y los comportamientos violentos; la sobreexposición puede producir alteraciones físicas como trastornos en el sueño, obesidad por falta de actividad y trastornos en el desarrollo del comportamiento; tiende a desensibilizar ante la violencia y conductas antisociales y agresivas, estimulando comportamientos, actitudes y antivalores; ratifica el uso de la violencia como método para resolver los problemas; fomenta la violencia, los actos sexuales, el abuso de drogas y el consumo del alcohol, entre otros. Además, podría incidir en los jóvenes más impresionables y desarrollar sintomatología traumática, estar asociado a la aparición en los adolescentes de ciertas conductas como las relaciones sexuales, el consumo de alcohol, tabaco y drogas, el timo, el robo y la conducción sin permiso; provoca aislamiento social progresivo y el abandono de las prioridades escolares. Asimismo, contenidos con mensajes e información inexactos o poco fiables podrían promover el machismo, xenofobia y pornografía; facilitar el contacto de los niños, las niñas o adolescentes con desconocidos a los cuales podrían brindarles datos e información personal o privada, o bien, evitar las normas de conductas que han aprendido respecto al no uso de la violencia, al imitar y adoptar las conductas que observan por la televisión. 
URL: http://www.una.ac.cr/educare

CORREO: educare@una.cr

García (2005) indica que la violencia televisiva tiene por características el ser gráfica, divertida, justificada y recompensada.

\section{La música y la violencia}

Redondo (s. f.b) argumenta que la música por siempre ha tenido un rol fundamental en el aprendizaje y la transmisión de la cultura y ha llegado a influir en las costumbres y emociones de las personas, así como en las tradiciones de un país o región, de ahí que el ascendiente que ha ejercido en los adolescentes y las adolescentes ha sido motivo de preocupación para la sociedad y las familias.

Partiendo de lo anterior, este autor señala la importancia que juega la publicidad, la cual ha demostrado que su poder puede tener mayor impacto que el que poseen los padres, la sociedad y los centros educativos. Fundamenta lo anterior en el hecho de que son cada vez menos los padres y madres que logran involucrarse eficaz y efectivamente en la crianza de los hijos e hijas y en la búsqueda de soluciones. Aunado a esto, está -en opinión del autor- la necesidad de independencia de los jóvenes de sus padres y familia, sustituyéndola con la dependencia que se experimenta hacia el grupo de pares. La influencia que este ejerza sobre el comportamiento, el vestuario o la música que el joven prefiera estará determinada por la madurez de cada persona.

De igual manera, este autor señala que la música puede desempeñar un papel importante en la socialización del grupo adolescente, convirtiéndose en un símbolo en su búsqueda de identidad y autonomía de la familia. Por ello, escuchar música y ver videos musicales son dos de las actividades más importantes durante la adolescencia. Se encuentra que ellos y ellas escuchan música desde que se levantan hasta que se acuestan e incluso muchos la emplean como fondo mientras duermen, estudian, en la ducha; cuando hacen los deberes; ayudan en las tareas de la casa; van en el bus, en carro, en moto; ven la televisión; hablan con los amigos; caminan y hasta en las reuniones sociales.

Para el autor, la preocupación mayor radica en que las letras de las canciones han aumentado el contenido que hace referencia al sexo, drogas, suicidio, muerte y satanismo. Esto incide significativamente en el comportamiento adolescente, pues provoca una desensibilización a la violencia, promueve roles sexuales estereotipados y una marcada aceptación de los comportamientos temerarios.

Redondo (s. f.b) encontró una correlación positiva entre la preferencia de la música Heavy Metal/Rock Duro y el comportamiento de los adolescentes y las adolescentes, destacándose este por el abuso de alcohol, la conducción a velocidades altas, abuso de drogas, promiscuidad sexual y actos de vandalismo. Agrega que en las fiestas el consumo del alcohol se da en la medida que los jóvenes y las jóvenes tienen una preferencia por escuchar la música a altos decibelios, lo que provoca que tengan que hablar alto, sequedad de la garganta, sed y deseo de beber para saciar esa sensación. 
También encontró que los adolescentes y las adolescentes con una tendencia al engaño, robo, fumar e intercambio sexual, entre otros, miran más televisión y escuchan la radio más a menudo que otros pares. "Cierto tipo de música, como heavy-metal y la rock-punky han sido relacionados con pensamientos suicidas, auto daño, abuso de sustancias y falta de respeto a la autoridad" (Redondo, s. f.b, Reacciones, sensaciones, emociones, párr. 3).

Complementa Redondo (s. f.b) que los videos musicales también tienen una importante influencia en la adolescencia, especialmente en quienes han sido criticados por promover la violencia, cierto tipo de baile, el crimen y la promiscuidad sexual, impacto que se acentúa con la identificación que tienen muchos adolescentes con los cantantes, quienes pueden actuar como modelos y llegar a ser idolatrados.

Sugiere este autor que a los jóvenes la música alternativa es la que podría serles más atractiva, en la medida que la consideran más profunda, sincera y significativa y como otra posibilidad a la música romántica. Este es un género con mucha influencia y sin reglas específicas, pues las letras tienden a ser abstractas, introspectivas y tan poéticas que a veces cuesta entender y seguir. La dificultad en interpretar sus mensajes es porque las ideas son contradictorias, es decir, que las letras tienden a plantear muchas preguntas acerca de las cuestiones de la vida, lo que gusta a los adolescentes, quienes buscan respuestas a sus interrogantes. La dificultad está en que se dan muy pocas respuestas y, cuando se dan, son poco esperanzadoras.

Continúa diciendo que el black metal, conocido como death metal, hardcore, y satan metal es el más preocupante para padres y educadores. Sus temas principales son el ocultismo, el dolor, la muerte y la violencia, y emplea como símbolos las calaveras, la sangre, instrumentos de tortura, luces rojas, humo y otros signos satánicos que contribuyen a crear una atmósfera infernal. Es más atractiva para los adolescentes con falta de autoestima, ya que podría darles una sensación de poder superior a sus propios problemas, concretamente si estas dificultades son con sus padres, docentes o compañeros.

Asimismo, refiere Redondo (s. f.b) que el thrash metal (metal que golpea) es el que tiene más seguidores, pues anima a la rebelión, la desesperanza y el caos. Los ritmos son histéricos y frenéticos. La música es poderosa, carente de orden y llena de rabia; sus letras lamentan el estado desesperanzado del mundo, la sociedad y todas sus instituciones, enfocándose en los horrores concretos del mundo, promoviendo la anarquía, la violencia e incluso la muerte y el suicidio como soluciones viables a un mundo colapsado.

Según este autor, la música que un adolescente elija y la emoción o respuesta que tenga variará según la edad, etnia, cultura, género del joven y grado de vulnerabilidad en que se encuentra. 
URL: http://www.una.ac.cr/educare

CORREO: educare@una.cr

\section{¿Cómo les afecta la música a las personas?}

Desde la perspeciva de la Església Bíblica d'Olot (s. f.) y Connecticut Clearinghouse. A Program of Wheeler Clinic (s. f.), los efectos positivos de la música en las personas menores de edad se podrían puntualizar en: define la vida de muchos adolescentes en la medida en que les brinda respuestas apropiadas y legítimas a las distintas situaciones, problemas y oportunidades que enfrentan en la cotidianidad, provocando un verdadero aprendizaje aún cuando aprender no es la razón principal por la que escuchan música; podría permitir conocer su alma, sus luchas, necesidades, su salud moral y espiritual, sus dudas y miedos; ayuda a definir la realidad; responde sus preguntas de forma excitante y atractiva; influye en el mundo que les rodea, en su visión de la vida; da forma a sus valores y actitudes, y juega un papel muy significativo en determinar en qué se convertirán cuando sean adultos y, finalmente, se dice que la música no representa un peligro para los adolescentes felices y saludables.

Aunado a lo anterior, la Església Bíblica d'Olot (s. f.) y la Familia Nova Schola (s. f.) plantean que algunos tipos de música podrían tener los siguientes efectos negativos en las personas jóvenes: los adolescentes absorben cualquier cosa, sin cuestionar su composición o el resultado que pueda tener en ellos; los videos han aumentado la habilidad de la música para moldear el comportamiento de los adolescentes, el mensaje es que se puede hacer lo que se quiera, con quien se quiera, cuando se quiera, donde se quiera y de la forma que se quiera; podría tender a llenar el sentimiento de soledad provocado por la ausencia o la indiferencia de los padres; alguna música enseña que la violencia es una forma legítima de tratar la ira justificada o injustificada; alguna música describe una relación amorosa con términos que nada tienen que ver con el amor tierno o romántico y combina la promiscuidad sexual con violencia, por lo que genera comportamientos que minimizan el valor de la persona y los estilos de vida. Además, las letras, vídeos y comentarios de los cantantes constantemente glorifican el abuso de drogas y el consumo de alcohol, lo cual, ante la tendencia de los adolescentes a rebelarse, conlleva a que prefieran aquella música que se enfrenta a las reglas establecidas, en la medida que expresa la desesperanza en la función familiar: "soy lo que tengo". Se agrega que el mensaje materialista de la música actual conlleva a que los adolescentes sean más activos sexualmente, violentos, materialistas y egoístas, ya que se les envía el mensaje de que esa es su realidad. Adicionalmente, podría definir su lenguaje, el pelo y estilo de vestir, puesto que imitan el modelo de sus héroes musicales; debido a que muchos videos musicales tienen contenidos violentos, provocan que los jóvenes vean el mundo como malvado y hostil, al negar la existencia de Dios y de reglas morales. Los artistas, mediante las letras de sus canciones, se visualizan a sí mismos como creadores de la verdad, por lo que transmiten el mensaje de que la verdad solo se puede encontrar dentro de cada persona misma. Ante esto, los adolescentes podrían experimentar una falta de esperanza al sentirse perdidos, solos, desconectados, frustrados y heridos; sentimientos reforzados por algunos videos en los que suelen aparecer mujeres sexualmente provocadoras, actos de rebeldía contra figuras de autoridad como los padres o maestros y escenas de desorden general. Además, la pasión por la música heavy-metal suele provocar comportamientos que denotan depresión, pensamientos suicidas, impulsividad, uso de drogas, delincuencia, distanciamiento de padres 
y colegio, cinismo, amoralidad, precocidad sexual y actitudes sexistas, entre otros; todos estos reforzados por las representaciones de los videos que podrían tender a presentar el suicidio como una solución a los problemas que se presenten y ciertos mensajes de las canciones que enfatizan el sexo mediado por el sadismo, el masoquismo, el incesto, los niños que menosprecian a las mujeres y la violencia contra ellas.

\section{Metodología}

\section{Tipo de estudio}

La investigación se realizó con un enfoque mixto, ya que combinó el análisis desde una perspectiva cualitativa y cuantitativa. Además, fue de carácter descriptiva, pues hace referencia a las opiniones y aportes de los informantes para conocer variados aspectos, dimensiones y componentes de la violencia. También es explicativa, porque pretendió dar un sentido de entendimiento al problema estudiado (Castro y Morales, 2009).

\section{Participantes}

El estudio se realizó en dieciocho centros educativos (11 de primaria y 7 de secundaria) localizados en las provincias de San José (Pérez Zeledón, Pavas y Cantón Central), Alajuela (San Carlos), Heredia (Cantón Central, San Antonio de Belén), Cartago (Cantón Central y Paraíso), Limón (Talamanca), Puntarenas (Golfito y Ciudad Neilly).

La población participante estuvo conformada por 390 estudiantes de los cuales 222 son niños y niñas de tercero, cuarto, quinto y sexto grados y de 168 estudiantes de secundaria que cursaban el octavo, noveno y undécimo años.

La selección de los participantes se realizó considerando los grupos superiores de las escuelas, (tercero a sexto grado), partiendo del criterio teórico que establece que en esta edad el aprendizaje de la lectoescritura está avanzado y, según la etapa de desarrollo en la que se encuentran, podría haber una mayor independencia al decidir la actividad a la que destinan su tiempo libre o de recreación. De igual manera, se escogieron los niveles superiores de secundaria para contrastar los resultados entre ambos grupos, y por considerar que en estos estudiantes la influencia de los medios de comunicación investigados podría ser mucho mayor.

Cabe mencionar que los centros educativos visitados para el estudio fueron elegidos a conveniencia, considerando los siguientes aspectos: el vínculo existente con las investigadoras por estarse realizando en ellos otras actividades académicas; el poco presupuesto con que se contaba para la ejecución del estudio y, especialmente, por la disposición de los diferentes actores de la comunidad educativa para conocer el impacto que tanto la música como la televisión y los videojuegos tenían en las personas menores de edad. 
URL: http://www.una.ac.cr/educare

CORREO: educare@una.cr

\section{Instrumentos}

Los instrumentos utilizados para la compilación de la información fueron dos cuestionarios, uno dirigido a niños y niñas de primaria, y otro a los estudiantes de secundaria. Ambos se estructuraron con preguntas tanto abiertas como cerradas, para un total de 24 preguntas para escolares y 27 para adolescentes.

Para la validación de los cuestionarios se recurrió a dos estrategias: primero se contó con el criterio de diez académicos conocedores de la temática y, luego, se aplicó a grupos de estudiantes con características similares a las de la muestra para valorar la comprensión o no de las preguntas contenidas en los instrumentos.

\section{Procedimientos}

Se procedió a realizar una búsqueda bibliográfica acerca del tema de la violencia manifestada a través de la música, la televisión y los videojuegos. Se seleccionó la población meta, para la cual se diseñaron los instrumentos antes mencionados y se programaron las visitas a los centros educativos precitados.

Seguidamente, se diseñó un taller que generara reflexión, análisis y concienciación acerca de la violencia presente en los medios de comunicación. La metodología seguida para la realización del taller incluyó las siguientes etapas: en primera instancia tenían que definir la violencia en general, por lo que se utilizó la técnica de lluvia de ideas combinada con materiales lúdicos; después se pasó un corto alusivo a la violencia en la televisión (para ello previamente se seleccionaron diversos segmentos de programas de televisión tales como: películas, fábulas, series, deporte, novelas, entre otros), los cuales fueron presentados a los estudiantes; posteriormente, se identificaron videojuegos con contenidos violentos y otros que no lo eran, y se les brindó un espacio para que los participantes jugaran con ellos, de manera que pudieran identificar la preferencia de unos u otros. Por último, para obtener datos acerca de la música, se les preguntó la canción preferida, la cual, una vez identificada, procedían voluntariamente a cantarla, comentando, además, el porqué les gustaba.

Una vez que se contó con la información, se procedió a elaborar los manuales con las respectivas categorías de análisis y las respectivas tablas para la descripción de los datos. A partir de ello se plantearon conclusiones y recomendaciones.

\section{Descripción y análisis de datos}

La tabla 1 refleja la conceptualización que de la violencia -y propiamente la violencia en los medios de comunicación- tienen los niños, niñas y adolescentes. Con el fin de facilitar la observación de las respuestas aportadas, estas se muestran agrupadas en una misma tabla; no obstante, al existir disparidad entre las frecuencias contenidas, no es conveniente establecer comparaciones. 
Tabla 1

Concepto de violencia que tienen los niños, las niñas y adolescentes

\begin{tabular}{|c|c|c|c|c|c|c|c|c|}
\hline \multirow[t]{2}{*}{ Categorías } & \multicolumn{2}{|c|}{ Frecuencia } & \multirow[t]{2}{*}{ Total } & \multirow[t]{2}{*}{$\%$} & \multicolumn{2}{|c|}{ Frecuencia Adolescentes } & \multirow[t]{2}{*}{ Total } & \multirow[t]{2}{*}{$\%$} \\
\hline & Niñas & Niños & & & Mujeres & Hombres & & \\
\hline Maltrato físico & 107 & 94 & 201 & 60.1 & 64 & 59 & 123 & 47.6 \\
\hline Maltrato verbal & 29 & 23 & 52 & 15.5 & 37 & 26 & 59 & 22.8 \\
\hline Abuso sexual & 19 & 23 & 42 & 12.5 & 4 & 1 & 5 & 1.9 \\
\hline $\begin{array}{l}\text { Matar, uso de armas, asalto, } \\
\text { robos }\end{array}$ & 12 & 14 & 28 & 8.3 & 2 & 3 & 5 & 1.9 \\
\hline $\begin{array}{l}\text { Juegos bruscos, televisión, } \\
\text { videojuegos }\end{array}$ & 4 & 3 & 7 & 2.0 & - & - & - & 0.0 \\
\hline Maltrato psicológico & 2 & 2 & 4 & 1.1 & 7 & 12 & 19 & 7.3 \\
\hline Actuar mal & - & - & - & 0.0 & 19 & 18 & 37 & 14.3 \\
\hline Otros & - & - & - & 0.0 & - & 2 & 2 & 0.7 \\
\hline No responde & 1 & 3 & 4 & 1.1 & - & 6 & 6 & 2.3 \\
\hline
\end{tabular}

Los niños, niñas y adolescentes definen violencia como maltrato físico, verbal, sexual o psicológico y como aquella acción que lesiona a otra persona, quien generalmente es más débil o indefensa. Otras respuestas con menor frecuencia involucran elementos como las armas para matar o maltratar a otras personas.

Partiendo de la bibliografía localizada, autores como la Organización Panamericana de la Salud y Organización Mundial de la Salud (2003) hacen referencia a que la violencia es el uso deliberado de la fuerza física o el poder y que causa lesiones, muerte, daño psicológico, trastornos del desarrollo o privaciones. Es decir, la definición que dan los niños, niñas y adolescentes es bastante coincidente, al señalar aspectos relacionados con el maltrato físico, psicológico, la muerte, el dominio de una persona sobre otra y el uso de la fuerza.

En el caso de adolescentes, estos tienen una visión más amplia de la violencia en sus diferentes ámbitos y dimensiones, ya que para ellos y ellas implica actuar mal, hacer daño, lastimar a otros, maltratar y hasta matar, lo cual es consecuente con el desarrollo moral esperado para la edad en la que se encuentran, en la cual hay una clara discriminación entre bien y el mal. De igual manera, cabe pensar que hay una mayor introyección del concepto de lo que implica la empatía ante el sufrimiento o daño que se le puede ocasionar a otra persona, mediante actos de violencia de diversa naturaleza; todo lo cual se traduce en el incumplimiento y violación del derecho que tienen todas las personas a ser respetados integralmente y a desenvolverse en contextos de paz. 
URL: http://www.una.ac.cr/educare

CORREO: educare@una.cr

Ante la problemática de la violencia, toda la sociedad civil tiene la responsabilidad de realizar cambios positivos basados en la solución de conflictos, el diálogo, el respeto la solidaridad y empatía, entre otros, con el fin de construir familias con principios y valores que coadyuven para que las personas menores de edad aprendan a interactuar y resolver, en forma no violenta, las situaciones conflictivas que se les presenten.

Como se mencionó antes, este artículo tiene como propósito exponer las opiniones de los niños, niñas y adolescentes con respecto a la violencia en los medios de comunicación, concretamente en la televisión, videojuegos y la música. En este sentido se les consultó por los programas de televisión favoritos de ellos y ellas, a lo que responden como se muestra en la tabla 2.

Tabla 2

Programas de televisión preferidos por los niños, niñas y adolescentes

\begin{tabular}{|c|c|c|c|c|c|c|c|c|}
\hline \multirow[t]{2}{*}{ Categorías } & \multicolumn{2}{|c|}{ Frecuencia } & \multirow[t]{2}{*}{ Total } & \multirow[t]{2}{*}{$\%$} & \multicolumn{2}{|c|}{ Frecuencia Adolescentes } & \multirow[t]{2}{*}{ Total } & \multirow[t]{2}{*}{$\%$} \\
\hline & Niñas & Niños & & & Mujeres & Hombres & & \\
\hline Fábulas & 56 & 65 & 121 & 35.3 & 30 & 49 & 79 & 25.0 \\
\hline Telenovelas & 39 & 2 & 41 & 11.9 & 37 & 11 & 48 & 15.2 \\
\hline Programas lucha libre & 4 & 27 & 31 & 9.0 & 7 & 7 & 14 & 4.4 \\
\hline Programas educativos & 17 & 5 & 22 & 6.4 & 7 & 2 & 9 & 2.8 \\
\hline Canal de cable & 6 & 15 & 21 & 6.1 & 9 & 2 & 11 & 3.4 \\
\hline Películas & 10 & 10 & 20 & 5.8 & 8 & 15 & 23 & 7.3 \\
\hline Noticias & 13 & 6 & 19 & 5.5 & 3 & 3 & 6 & 1.9 \\
\hline Programas cómicos & 5 & 10 & 15 & 4.3 & 11 & 10 & 22 & 6.9 \\
\hline Videos de música & 11 & 1 & 12 & 3.5 & 19 & 6 & 25 & 7.9 \\
\hline Series & 5 & 6 & 11 & 3.2 & 19 & 20 & 39 & 12.3 \\
\hline Canales nacionales & 6 & 5 & 11 & 3.2 & 2 & - & 2 & 0.6 \\
\hline Programas deportivos & - & 7 & 7 & 2.0 & 1 & 11 & 12 & 3.8 \\
\hline Todos & 3 & 3 & 6 & 1.7 & 2 & 13 & 15 & 4.7 \\
\hline Programas religiosos & 1 & 1 & 2 & 0.5 & 5 & - & 5 & 1.5 \\
\hline Ninguno & - & 1 & 1 & 0.2 & - & 2 & 2 & 0.6 \\
\hline Otros: animé, scrumbs & - & - & - & - & 2 & 1 & 3 & 0.9 \\
\hline No responde & - & 2 & 2 & 0.5 & - & - & - & - \\
\hline
\end{tabular}


Más de la tercera parte de los niños y niñas participantes mencionan que los programas más vistos por ellos son las fábulas, algunas de las cuales podrían catalogarse como violentas por ejemplo Dragon Ball Z, Pókemon y Padrinos mágicos, así como otras no consideradas violentas tales como la Chica Fresita, Little Pony y Dora, la exploradora.

Otro grupo importante de niñas señalan que les gusta ver telenovelas, tanto las que están dirigidas a adolescentes y niños (Floricienta, Frijolito, Amigos por siempre); como las que se supone son para adultos, en su opinión por el horario en que se presentan y por las escenas y contenido (Besos robados, Los Reyes, La tormenta, El cuerpo del deseo).

Cabe señalar que solamente dos niños hacen alusión a las telenovelas. Sin embargo, 27 de ellos señalan que ven programas de lucha libre como la "WWF" y "Smack Down". En menor porcentaje se mencionan los programas educativos, noticias, cómicos, videos de música, deporte y religiosos. Un niño subraya que no ve nada porque los programas de televisión "son horribles".

En el caso de los adolescentes y las adolescentes, se mantienen las dos primeras categorías fábulas y telenovelas, coincidiendo con los niños y niñas, así como la preferencia de las mujeres por las novelas, aunque aumenta el porcentaje de hombres que las ven. En tercer lugar de preferencia aparecen las series tales como: Roswell, "OC", Smallville, Zona muerta, Sétimo cielo, entre otras; este tipo de programas es visto casi en porcentajes iguales por hombres y mujeres.

Los videos de música, las películas de acción, terror o ficción y los programas cómicos son mencionados por un porcentaje importante de muchachos y muchachas. Con frecuencias inferiores se anotan los programas de lucha libre, educativos, deportivos y religiosos. Solo en una respuesta se menciona que no ve nada con respecto a los programas de televisión.

Los mensajes transmitidos por los diferentes programas y anuncios comerciales podrían impactar negativamente en el proceso de socialización, el aprendizaje, el desarrollo integral y la el desarrollo de violencia, por cuanto hay una alteración entre la realidad y fantasía, lo que conlleva a una desensibilización antes las diferentes manifestaciones de la violencia, así como la invisibilización del impacto que esta tiene en las personas que la sufren.

Los datos contenidos en la tabla anterior son preocupantes, especialmente porque, como bien señala Levine (1997), los personajes representados en los diferentes medios de comunicación, en su mayoría, desempeñan roles que modelan conductas caracterizadas por antivalores como el sufrimiento, la humillación, los celos, la envidia, la pereza, la deshonestidad, la rivalidad, el dominio, las demostraciones de fuerza, entre otros, como una forma de obtener beneficio propio -incluso a costa de la vida e integridad de quienes están a su alrededor-.

Adicionado a lo anterior, durante los programas precitados, las personas menores de edad están expuestas a los mensajes explícitos o subliminales contenidos en los anuncios comerciales, lo cual correlaciona positivamente con el consumo de bebidas alcohólicas, las drogas lícitas e ilícitas, la precocidad sexual y, en algunos casos, con la distorsión del concepto de relación sexual y sus implicaciones emocionales, físicas y sociales. Esto, por cuanto asumen que son violentas, 
URL: http://www.una.ac.cr/educare

CORREO: educare@una.cr

superficiales, no sostenidas en el tiempo, indiscriminadas, sin protección y sin el sentido de responsabilidad con que debería asumirse la actividad sexual.

Ante este panorama, cabe esperar que tanto los padres como las madres y docentes, y otros adultos responsables de las personas menores de edad conozcan los programas de televisión, así como los contenidos y mensajes que estos transmiten. De igual manera, que reflexionen y analicen en conjunto aquellos cuyo tema central gira en torno a la violencia.

Seguidamente, en la tabla 3 se presenta la mirada de los niños, niñas y adolescentes con respecto al contenido o no de violencia en los programas de televisión.

Tabla 3

Valoración de los niños, niñas y adolescentes sobre el contenido violento o no de los programas de televisión

\begin{tabular}{|c|c|c|c|c|c|c|c|c|}
\hline \multirow[t]{2}{*}{ Categorías } & \multicolumn{2}{|c|}{ Frecuencia } & \multirow[t]{2}{*}{ Total } & \multirow[t]{2}{*}{$\%$} & \multicolumn{2}{|c|}{ Frecuencia Adolescentes } & \multirow[t]{2}{*}{ Total } & \multirow[t]{2}{*}{$\%$} \\
\hline & Niñas & Niños & & & Mujeres & Hombres & & \\
\hline Sí & 56 & 77 & 133 & 59.1 & 42 & 64 & 106 & 62.7 \\
\hline No & 55 & 35 & 90 & 40 & 38 & 25 & 63 & 37.2 \\
\hline No responde & 1 & 1 & 2 & 0.8 & - & - & - & - \\
\hline
\end{tabular}

A la pregunta de que si los programas de televisión que ven son violentos, los niños y niñas responden en un $60 \%$ que sí lo son, y un $40 \%$ considera que no. Este $60 \%$ plantea que son violentos porque se golpean, "hay cosas sexuales...", cachetadas, son de lucha, pelean, pleitos, mal vocabulario, ataques, matan niños, agreden, gritan, sangriento, disparan, matanza, sufrimiento, entre otros.

Por el contrario, las razones de por qué no son violentos se refieren a diversión, amistad, enseñanzas, son de niños, son noticias, cosas buenas. Algunas de las justificaciones de los niños y niñas llaman la atención, por ejemplo: "no para mi las novelas tratan de amor", "todo lo contrario las novelas ayudan". Con lo anterior, se hace evidente la función necesaria del adulto como orientador de los niños pequeños acerca del contenido de los programas de televisión. Esto es preocupante, porque reafirma lo expresado por Huerta (2005) acerca de que la influencia de la televisión es significativamente alarmante, ya que las personas menores de edad adolecen del sentido de la capacidad para decidir por sí mismas cuáles son los contenidos de los programas que más les benefician o perjudican. 
Los adolescentes y las adolescentes reconocen en un $62.7 \%$ que el contenido de los programas de televisión que ven son violentos, porque hay peleas, cosas vulgares, son luchas, matanza, se dicen malas palabras, matan y golpean, hay mucha sangre, irrespeto y machismo, entre otros.

Por otra parte, el $37.2 \%$ piensa que no son violentos los mensajes de los programas de televisión que ven porque son educativos, buscan la felicidad de las personas, es música, deja mensajes, son situaciones cotidianas, son cristianos de Dios, no agreden y son importantes.

Coincidentemente, ambos grupos participantes reconocen que ven programas violentos, "fuertes", "vulgares", "se dicen malas palabras", "matanzas", entre otros, pero pareciera no ser un motivo por el cual se dejen de ver estos programas. Al respecto, Leiva (s. f.) sugiere que la televisión, por lo general, desempeña el papel que le corresponde a la familia en la crianza de los hijos, por cuanto esta delega la responsabilidad que le corresponde en la formación de las personas menores de edad. Además, la televisión tiende a organizar y ocupar el tiempo libre; promueve un falso sentido de identidad; les indica a los niños, niñas y adolescentes lo bueno y lo malo, basándose en una escala de valores que se espera pongan en práctica, tanto con los amigos como en los juegos y en los roles sociales que deben representar.

Al respecto, las suscritas son de la opinión de la importancia de que los padres, madres o responsables de los niños, niñas y adolescentes estén pendientes de los contenidos y mensajes que se transmiten en televisión, pues, sin un análisis crítico, podrían conllevar a que las personas menores de edad sean manipuladas y colocadas en una posición de vulnerabilidad e individualismo que les incita a tomar decisiones relacionadas con al consumismo y a imitar valores y patrones de conducta negativos.

En la pregunta que indagó acerca de la percepción de la violencia que observan en la televisión y en la vida real, mencionan que la violencia en la televisión es falsa, ficticia, actuada, irreal y con efectos especiales (mencionado por 86 niños y niñas); además opinan que la violencia en la televisión no perjudica a nadie, no causa daños, no se siente nada, no mueren, "solo lo ves y no lo sientes" y son muñecos, entre otras respuestas (señalado por 33 niños y niñas). Llama la atención la respuesta "todo lo que pasa ahora se ve en la televisión", refiriéndose a que la violencia de los programas de televisión no dista mucho de la que vivencian cotidianamente.

Al respecto los adolescentes y las adolescentes piensan que la violencia en la televisión es ficticia, es actuada, "solo se ve no se siente" (37.3\%), la televisión enseña la violencia, "en la tele se aprende", "la televisión transmite la violencia", "se aprende a agredir" (8\%) y consideran que no perjudica a nadie, "no afecta a nadie", "no importa", "puede cambiarse" (4\%). En el caso de la violencia en la vida real, no hay ninguna diferencia, según el $15.1 \%$ de los participantes, ya que pasa lo mismo que en la realidad, hacen lo mismo e influye mucho en la realidad; otros consideran que es algo que ocurre en verdad (13.1\%), que afecta a las personas porque 
URL: http://www.una.ac.cr/educare

CORREO: educare@una.cr

causa dolor, sufrimiento, se siente, daña, causa angustia, trae demasiadas pérdidas de vidas y problemas.

Las respuestas dadas reflejan que los participantes reconocen que la violencia en la televisión es irreal y coinciden con la bibliografía revisada en cuanto a que la exposición reiterada a la violencia repercute negativamente en su desarrollo y bienestar. Además, se confirma el que los niños y niñas son considerados excelentes imitadores de conductas, situación que es fácilmente observable en los juegos durante el recreo, momento en el que se pone en práctica lo aprendido de los videojuegos y programas de televisión que observan.

A continuación, en la tabla 4 se presentan las opiniones de los participantes y las participantes con respecto a los videojuegos.

Tabla 4

Tenencia de videojuegos en el hogar por parte de niños, niñas y adolescentes

\begin{tabular}{|c|c|c|c|c|c|c|c|c|}
\hline \multirow[t]{2}{*}{ Categorías } & \multicolumn{2}{|c|}{ Frecuencia } & \multirow{2}{*}{ Total } & \multirow{2}{*}{$\%$} & \multicolumn{2}{|c|}{ Frecuencia Adolescentes } & \multirow{2}{*}{ Total } & \multirow{2}{*}{$\%$} \\
\hline & Niñas & Niños & & & Mujeres & Hombres & & \\
\hline Sí & 44 & 80 & 124 & 55.6 & 24 & 60 & 84 & 50.2 \\
\hline No & 62 & 31 & 93 & 41.7 & 54 & 27 & 81 & 48.5 \\
\hline No responde & 2 & 4 & 6 & 2.6 & 1 & 1 & 2 & 1.1 \\
\hline
\end{tabular}

En la tabla anterior se observa que la mayoría de los niños y niñas tienen posibilidades de jugar videojuegos en sus hogares (55.6\%), quienes no pueden se las agencian, ya sea pagando o jugando con amigos, para tener acceso a este tipo de tecnología (41.7\%). Además, la mayoría de los juegos mencionados tienen un matiz violento, ellos mismos justifican que aunque son violentos ellos "no aprenden"; sin embargo, deben "matar para recuperar la reina", "destruir autos" y "pelear".

El 50\% de los adolescentes tienen videojuegos en su hogar, mencionan más el tipo de artefacto que utilizan por ejemplo play station, Wii, computadora, que los nombres específicos de los juegos. Sin embargo, los nombres de los videojuegos que especifican denotan contenidos violentos.

Como puede observarse, en los varones niños y adolescentes hay una alta tendencia a la preferencia de los videojuegos en comparación con las niñas y las adolescentes, lo cual es consecuente con la realidad, dado que en los comercios que los diseñan y ofrecen, la tendencia es a encontrar una mayor cantidad y diversidad de juegos dirigidos a los varones $y$, en menor grado, a las mujeres. 
Se les solicitó a los niños, niñas y adolescentes que clasificaran, según su género, los videojuegos que prefieren, listado que se presenta en la tabla 5.

Tabla 5

Clasificación de los videojuegos preferidos por los niños, niñas y adolescentes

\begin{tabular}{|c|c|c|c|c|c|c|c|c|}
\hline \multirow[t]{2}{*}{ Categorías } & \multicolumn{2}{|c|}{ Frecuencia } & \multirow{2}{*}{ Total } & \multirow{2}{*}{$\%$} & \multicolumn{2}{|c|}{ Frecuencia Adolescentes } & \multirow{2}{*}{ Total } & \multirow{2}{*}{$\%$} \\
\hline & Niñas & Niños & & & Mujeres & Hombres & & \\
\hline Acción & 31 & 68 & 99 & 29.9 & 30 & 53 & 83 & 31.3 \\
\hline Terror & 35 & 49 & 84 & 25.3 & 30 & 35 & 65 & 24.5 \\
\hline Educativos & 36 & 22 & 58 & 17.5 & 19 & 9 & 28 & 10.5 \\
\hline Todos, cualquiera & 28 & 21 & 49 & 14.8 & 6 & 38 & 44 & 16.6 \\
\hline Sexuales & - & 15 & 15 & 4.5 & - & 8 & 8 & 3.0 \\
\hline Ninguno & 17 & 7 & 24 & 7.2 & 26 & 3 & 29 & 10.9 \\
\hline No responde & 1 & 1 & 2 & 0.6 & 3 & 2 & 5 & 1.8 \\
\hline Todos no sexuales & - & - & - & - & 2 & - & 2 & 0.7 \\
\hline Fútbol & - & - & - & - & - & 1 & 1 & 0.3 \\
\hline
\end{tabular}

En relación con los gustos por videojuegos, tanto niños y niñas, como adolescentes mencionan que tienen preferencia por temas de acción; el terror en segundo lugar y, con porcentajes más bajos, mencionan los videojuegos educativos, por la mayoría de las mujeres. Algunos indican que sienten gusto por cualquier videojuego, ya que les atrae jugar sin interesar si son de acción, educativos o con contenido sexual, entre otros.

En el caso de los niños y niñas, solo el $7.2 \%$ alude que no le gustan los videojuegos y con respecto a los adolescentes solo un $10.9 \%$ no gusta de ninguno.

Cabe reflexionar acerca de por qué si los padres, madres o encargados de las personas menores de edad son los proveedores económicos para la adquisición del videojuego, no son lo suficientemente responsables y asertivos a la hora de decidir el contenido del videojuego al que van a exponer a sus hijos. Ante esta situación, es imperativa la concienciación de los adultos acerca del daño que están provocando en las personas menores de edad a las cuales es su deber proteger.

Seguidamente se presenta la tabla 6 que refleja las opiniones de las personas menores de edad acerca de si los contenidos de los videojuegos son o no violentos. 
URL: http://www.una.ac.cr/educare

CORREO: educare@una.cr

Tabla 6

Opinión de los niños, niñas y adolescentes acerca del contenido violento en los videojuegos

\begin{tabular}{|c|c|c|c|c|c|c|c|c|}
\hline \multirow[t]{2}{*}{ Categorías } & \multicolumn{2}{|c|}{ Frecuencia } & \multirow{2}{*}{ Total } & \multirow{2}{*}{$\%$} & \multicolumn{2}{|c|}{ Frecuencia Adolescentes } & \multirow{2}{*}{ Total } & \multirow{2}{*}{$\%$} \\
\hline & Niñas & Niños & & & Mujeres & Hombres & & \\
\hline Sí & 73 & 85 & 158 & 70.2 & 39 & 62 & 101 & 59.4 \\
\hline No & 32 & 20 & 52 & 23.1 & 22 & 21 & 43 & 25.2 \\
\hline Mas o menos & 5 & 4 & 9 & 4 & 4 & 2 & 6 & 3.5 \\
\hline No responde & - & 6 & 6 & 2.6 & 15 & 5 & 20 & 11.7 \\
\hline
\end{tabular}

En relación con el contenido violento o no de los videojuegos, se nota que el $70.2 \%$ de los niños y niñas opinan que estos sí tienen contenido violento y solo un $23.1 \%$ comenta que no. Ellos y ellas tienen claridad acerca del contenido violento de los videojuegos, por eso comentan que se "matan entre ellos", "hay que matar para ganar", "dan miedo", "pelean", "golpean", "la mente se perturba", hay "pistolazos", "sangre", "disparar", "le cortan la cabeza", "lastiman", son "agresivos", son "malos" y "nos manipulan", entre otras respuestas que brindan al respecto.

En el caso de los que anotan que no son violentos, pareciera que los padres o madres tienen mayor protagonismo en la escogencia y compra de los videojuegos de sus hijos o hijas, ya que señalan que son educativos, que los papás "compran juegos que no dañan la mente", porque "divierten" y "son para entretener".

Los adolescentes y las adolescentes mencionan casi en un $60 \%$ que los videojuegos sí son violentos porque "maltratan", "golpean", hay "masacres", "peleas", "armas" "muerte", "hay que matar a los enemigos para poder avanzar", "mucha sangre", "transmiten malos pensamientos" y hay "ataques sangrientos y roban carros".

Solo un $25.2 \%$ de los adolescentes creen que no tienen contenido violento, porque son educativos, ayudan a aprender jugando, es fútbol y solo se pasa pantallas en el juego, entre otros.

En general, los porcentajes tanto de niños y niñas como de adolescentes son similares, en cuanto a que los videojuegos tienen contenido violento. Ante esta dramática situación es una realidad que el ejercicio de la paternidad y maternidad responsables es impostergable, por lo que, en el seno familiar, se debe conocer los procedimientos de los juegos de sus hijos e hijas; leer las instrucciones que viene con los videojuegos; discutir con ellos y ellas el contenido del juego; prestar atención a los sistemas de puntaje de los juegos de video; observarlos jugar y periódicamente participar con ellos en los juegos; establecer guías explícitas acerca del uso y el tiempo para utilizar los videos; enseñarles a identificar las diferencias entre los episodios de violencia que observan en los medios de comunicación y los que experimentan en la realidad; 
supervisarlos mientras están jugando y protegerlos de la violencia excesiva, advirtiéndoles acerca del potencial peligro que podrían representar los contactos y relaciones mientras están jugando juegos en línea.

Para conocer el tipo de música que escuchan las personas menores de edad, se presenta la tabla 7.

Tabla 7

Tipo de música que escuchan los niños, niñas y adolescentes

\begin{tabular}{|c|c|c|c|c|c|c|c|c|}
\hline \multirow[t]{2}{*}{ Categorías } & \multicolumn{2}{|c|}{ Frecuencia } & \multirow{2}{*}{ Total } & \multirow{2}{*}{$\%$} & \multicolumn{2}{|c|}{ Frecuencia Adolescentes } & \multirow{2}{*}{ Total } & \multirow{2}{*}{$\%$} \\
\hline & Niñas & Niños & & & Mujeres & Hombres & & \\
\hline Reggaetón & 51 & 58 & 99 & 32.8 & 30 & 17 & 47 & 16.0 \\
\hline Románticas & 23 & 6 & 29 & 9.6 & 27 & 13 & 40 & 13.6 \\
\hline Regué & 14 & 13 & 27 & 8.9 & 12 & 13 & 25 & 8.5 \\
\hline Rock & 3 & 24 & 27 & 8.9 & 20 & 28 & 48 & 16.4 \\
\hline Cristiana & 13 & 9 & 22 & 7.3 & 16 & 5 & 21 & 7.1 \\
\hline Pop & 16 & 4 & 21 & 6.9 & 13 & 6 & 19 & 6.5 \\
\hline Variados & 15 & 6 & 21 & 6.9 & 13 & 10 & 23 & 7.8 \\
\hline Salsa & 10 & 2 & 12 & 3.9 & 10 & 1 & 11 & 3.7 \\
\hline Hip Нop & 2 & 6 & 8 & 2.9 & 2 & 5 & 7 & 2.3 \\
\hline Cumbia & 7 & 2 & 9 & 2.6 & 5 & 3 & 8 & 2.7 \\
\hline Rancheras & 1 & 2 & 3 & 0.9 & & & & \\
\hline Bachata & 2 & - & 2 & 0.6 & 2 & 1 & 3 & 1.0 \\
\hline Merengue & 1 & - & 1 & 0.3 & 5 & 1 & 6 & 2.0 \\
\hline Punk & - & 1 & 1 & 0.3 & 3 & - & 3 & 1.0 \\
\hline Dance Hall & 1 & - & 1 & 0.3 & 4 & 4 & 8 & 2.7 \\
\hline Todo excepto rock & - & - & - & - & 3 & 6 & 9 & 2.9 \\
\hline Clásica, la tranquila & - & - & - & - & 5 & 3 & 8 & 2.7 \\
\hline Rap & - & - & - & - & - & 3 & 3 & 1.0 \\
\hline Nada "no me gusta" & 2 & 8 & 10 & 3.3 & - & 4 & 4 & 1.3 \\
\hline Electrónica & - & - & - & - & 1 & - & 1 & 0.3 \\
\hline No responde & 1 & 7 & 8 & 2.6 & - & - & - & - \\
\hline
\end{tabular}


URL: http://www.una.ac.cr/educare

CORREO: educare@una.cr

En ambos grupos de participantes se nota gran diversidad en cuanto a los géneros de música preferida. No obstante, señalan al reggaetón, rock, románticas y regué, como las más escuchadas.

El 25.5\% de los niños y niñas participantes anotan que la música tiene contenido violento, en tanto que el $66.8 \%$ considera que la música no es violenta, dado que "son canciones románticas", depende de "cómo se interprete", "no disparan" y no "golpean a nadie".

Quienes sí piensan que el contenido es violento, dicen que es porque "hay peleas", "quiebran vidrios", se dicen "malas palabras", se "atacan", hay "gritos", se "mata a otros", se "jalan el pelo", "hablan vulgaridades", "regañan", "dicen cosas malas", "armas", "golpes", "peleas sangrientas", "el reguetón tiene contenido violento y sexual" y se "viola gente", entre otros.

En cuanto al porqué les agrada o no este tipo de música los adolescentes y las adolescentes mencionan, en primer lugar, el ritmo, como suena, el sonido (25.2\%); la letra, el sentimiento que transmite, su contenido, la forma de cantar, la música que cantan (21.6\%); "todo, todo me gusta" (12.3\%); el mensaje que tiene, tiene mensajes muy bonitos y buenos mensajes (7.2\%). Para el $6,7 \%$ "no es violenta", es "tranquila, relajante" y "se siente mejor cuando escucha". "Es de Dios", "te llena un vacío, amor, paz, esperanza hacia mi Dios", según el 4.1\%. Para el 3.0\%, "habla la verdad", hay "sinceridad en la letra", "pasan en la vida real" y "entiendes lo que dicen". Se "pueden bailar", "inyecta" y "es bonita" para el 7.5\% y "me divierte", "es variada" y por la "ropa" para el 4\%.

Autores como Redondo (s. f.b) opinan que "...la música siempre ha desempeñado un papel importante en el aprendizaje y la cultura, pudiendo llegar a influir en costumbres y emociones" (párr. 1). De igual manera tiene un rol protagónico en el proceso de socialización y como referente en la conformación de la identidad, la autonomía y identificación con sus iguales.

En relación con lo antes planteado, las investigadoras reiteran la necesidad de que los padres, las madres de familia, docentes y otros adultos responsables de las personas menores de edad se informen acerca de los tipos de música, las particularidades de cada género, el contenido de las letras, las reacciones, emociones y sensaciones que esta provoca; así como las razones por las que ellos y ellas se sienten atraídos, de manera que puedan enseñarles a identificar aquella que legitima la violencia como medio para manejar la ira justificada o injustificada.

Lo anterior es importante especialmente porque, como bien plantea la Església Bíblica d'Olot (s. f), las letras de las canciones podrían tender a enseñar que el placer sexual es un fin por sí mismo, conduciéndoles a buscar el amor y las relaciones solamente por el camino de la intimidad sexual, enfatizando los aspectos físicos en detrimento de los factores emocionales y combinando la promiscuidad sexual con la violencia, lo cual, no cabe duda, promueve comportamientos que conllevan a la desvalorización de la persona.

Asimismo, el autor precitado resalta que los tipos de música más populares entre los jóvenes hoy en día son coincidentes con los indicados por los sujetos participantes en este estudio, los cuales son considerados inofensivos comparados con otros. No obstante, sugiere en las personas menores de edad estereotipos erróneos acerca de lo que es una mujer sexy, deseable, hermosa y la visualiza como objeto sexual. Adicionalmente, Redondo (s. f.b) muestra preocupación ante el hecho de que 
las letras de la mayoría de las canciones tienden a tener contenidos violentos y mensajes sugestivos relacionados con el crimen, el sexo, las drogas, el suicidio, la muerte y el satanismo, lo que se confirma con las respuestas aportadas por quienes brindaron información para esta investigación. Esta situación es más preocupante aún si se toma en cuenta lo estipulado por el autor acerca del impacto de los videos musicales, ya que intervienen más los sentidos, convirtiéndolos en herramientas mucho más efectivas de persuasión, debido a que influyen en la cultura de los espectadores alterándoles los patrones de comportamiento.

Seguidamente, se muestra la tabla 8 con las respuestas de los niños, niñas y adolescentes acerca de cuáles son los pasatiempos a los que dedican más tiempo.

Tabla 8

Pasatiempos a los que dedican más tiempo los niños, las niñas y adolescentes

\begin{tabular}{|c|c|c|c|c|c|c|c|c|}
\hline \multirow[t]{2}{*}{ Categorías } & \multicolumn{2}{|c|}{ Frecuencia } & \multirow{2}{*}{ Total } & \multirow{2}{*}{$\%$} & \multicolumn{2}{|c|}{ Frecuencia Adolescentes } & \multirow{2}{*}{ Total } & \multirow{2}{*}{$\%$} \\
\hline & Niñas & Niños & & & Mujeres & Hombres & & \\
\hline Música & 65 & 44 & 109 & 25.9 & 67 & 60 & 127 & 23.8 \\
\hline Televisión & 57 & 51 & 108 & 25.7 & 55 & 68 & 123 & 23 \\
\hline Deportes & 20 & 59 & 79 & 18.8 & 24 & 55 & 79 & 14.8 \\
\hline Video juegos & 9 & 58 & 67 & 15.9 & 10 & 55 & 65 & 12.1 \\
\hline Bailes & 19 & 10 & 29 & 6.9 & 25 & 7 & 32 & 6.0 \\
\hline Internet & - & - & - & - & 10 & 16 & 26 & 6.1 \\
\hline Disfrutar en calle & - & - & - & - & 24 & 37 & 61 & 11.4 \\
\hline Grupo religioso & - & - & - & - & 28 & 10 & 38 & 7.1 \\
\hline Barra deportiva & - & - & - & - & 2 & 6 & 8 & 1.5 \\
\hline No responde & - & - & - & - & - & 2 & 2 & 0.4 \\
\hline
\end{tabular}

Los niños, niñas y adolescentes coinciden al anotar que las actividades a las que dedican mayor cantidad de tiempo son escuchar música, ver televisión, practicar deportes y jugar con videojuegos, con los porcentajes más altos.

En el caso de los niños y niñas, resalta que practican bailes y juegan o navegan en Internet, en tanto que los adolescentes y las adolescentes gustan de disfrutar en la calle, de asistir a grupos religiosos o iglesias y unos pocos mencionan que forman parte de una barra deportiva.

Analizando los pasatiempos y contrastándolos con los niveles de violencia que ellos mismos han mencionado tiene la música, la televisión, internet y los videojuegos, se podría pensar que los adolescentes y niños están expuestos a gran cantidad de contenidos violentos en contraposición con los juegos y actividades al aire libre o en grupos sociales. 
URL: http://www.una.ac.cr/educare

CORREO: educare@una.cr

Las investigadoras son del criterio de la importancia de enseñar a las personas menores de edad a tomar decisiones en cuanto a la elección asertiva de las actividades que realizan y en la administración del tiempo de ocio. El buen uso que se le dé al tiempo de ocio es considerado una habilidad para la vida y no como se tiende a pensar que es una pérdida del tiempo. Muestra de ello es que la sociedad actual lo ha incorporado con mayor permisividad en el ámbito personal y profesional.

Respecto a este mismo tema, Redondo (s. f.b) enfatiza que el escuchar música y ver videos musicales son las dos actividades más importantes para los adolescentes. Este autor menciona un estudio realizado por el Centro de Investigaciones de la Realidad Social (s. f.), el cual evidenció que los jóvenes dedican su tiempo libre prioritariamente a las siguientes actividades: televisión $62 \%$, lectura $29 \%$, deporte $28 \%$, cine $19 \%$, dato que es coincidente con los hallazgos de esta investigación, excepto en lo que a la lectura se refiere, ya que para el caso de Costa Rica ninguna persona menor de edad lo anotó como actividad a la cual destina tiempo libre.

Una vez conocida la concepción de los niños, niñas y adolescentes acerca de qué es la violencia y sus niveles de acción en los medios de comunicación, se procede a formular una serie de conclusiones y recomendaciones al respecto.

\section{Conclusiones}

Las personas menores de edad definen la violencia como maltrato físico, verbal, sexual y psicológico; señalan que la violencia lastima a las personas más débiles e indefensas, por lo cual coinciden con las concepciones teóricas presentadas en el documento en cuanto a la presencia de elementos como maltrato físico, psicológico, dominio de una persona sobre otra y uso de la fuerza.

Los programas de televisión más gustados por los niños y niñas son las fábulas, las telenovelas y los espacios de lucha libre, también preferidos por el grupo de adolescentes, quienes adicionan las series y los videos musicales.

Los niños, niñas y adolescentes identifican que los programas de televisión de su escogencia presentan contenidos violentos. Si bien logran discriminar que estos hechos violentos no son reales, sí señalan que a través de la televisión se aprende la violencia.

La mayoría de las personas menores de edad consultadas informan que tienen videojuegos en sus hogares y los que no los tienen, frecuentan los lugares donde existen, ya sea alquilándolos o compartiendo con sus amigos.

Los niños, niñas y adolescentes parecen tener claridad de que la violencia en la televisión no es real, sino ficticia; sin embargo, opinan que este tipo de violencia enseña patrones de comportamiento violento. Con respeto a la violencia en la vida real, sugieren que si bien es ficticia, no hay mucha diferencia con la presentada por la televisión, ya que esta influye y causa mucho dolor.

Los temas de los videojuegos que más eligen los niños, niñas y adolescentes están relacionados con la acción, el terror y, en menor porcentaje, los videojuegos educativos. 
Para la mayoría de los participantes, el contenido de los videojuegos escogidos por ellos y ellas es violento y mencionan que para ganar, en estos, se debe pelear o matar.

Los géneros musicales que escuchan los niños, niñas y adolescentes son variados. Entre los preferidos están el reggaetón, rock, románticas y regué. Indican que les gusta este tipo de música por el ritmo, el sonido, la letra, el contenido y el sentimiento que transmite, entre otros.

La mayoría de los niños, niñas y adolescentes señalan que sus pasatiempos preferidos son escuchar música, ver televisión, practicar deportes y jugar con el video juego, elección que conlleva a que las personas menores de edad estén expuestas a contenidos violentos.

\section{Sugerencias para la prevención de la violencia en los diferentes ámbitos en que se desenvuelven los niños, niñas y adolescentes}

Se anotan a continuación una serie de sugerencias derivadas de la investigación y de la revisión teórica, a fin de orientar a los adultos en la prevención de la violencia que transmiten los medios de comunicación (televisión, videojuegos y música) a las niñas, niños y adolescentes que los accesan.

1. En los centros educativos es imperativo contar con un currículo apropiado para brindar atención oportuna a las necesidades emocionales del estudiantado y una educación dirigida a la enseñanza del manejo de las emociones negativas, de las conductas problemáticas; a potenciar el desarrollo de las habilidades pro-sociales; a conocer acerca del desarrollo integral y favorecer una disciplina apropiada; así como brindar una educación a las figuras parentales, en temas relacionados con el desarrollo integral de sus hijas e hijos, la vinculación afectiva, los patrones de crianza y la comunicación, temáticas que favorecen la protección de la prole.

2. Los centros educativos deben contar con servicios cuya finalidad sea la temprana y rápida identificación de niños, niñas y adolescentes que interactúan en forma violenta con su medio social, que viven en ambientes agresivos y que están influenciados por los programas televisivos, video juegos o la música, para poder proveerles de experiencias educativas apropiadas e intervenciones psicológicas oportunas.

3. Los centros educativos deben propiciar que se enseñe a las personas menores de edad a resolver los diferentes conflictos que se les presenta de forma pacífica y constructiva, de manera que se promueva su óptimo desarrollo integral.

4. El personal docente debe analizar con sus estudiantes la influencia negativa de la violencia que transmiten los medios de comunicación y cómo esta influye tanto en sus relaciones como en la comunicación cotidiana, de manera que estén preparados para que comprendan y enfrenten mejor las diferentes situaciones que se les presentan en los ámbitos en que se desenvuelven.

5. Las figuras parentales deben evitar que los hijos y las hijas usen los videojuegos en su habitación y se aíslen; en su lugar, podrían propiciar juegos de mesa para toda la familia, lecturas compartidas y salidas interesantes para todos. 
URL: http://www.una.ac.cr/educare

CORREO: educare@una.cr

6. Los padres, madres o encargados deben ver la televisión con las personas menores de edad, para que conozcan y comprendan los contenidos de los diferentes programas, disminuyan la creencia y reproducción de los estereotipos, aumenten la conducta pro social, vean la televisión con un propósito crítico y educativo, cuenten con otras alternativas culturales y recreativas, desarrollen el hábito de la lectura, analicen educativamente los contenidos de los programas que les gustan, hagan buen uso del tiempo de ocio, entiendan que la televisión está al servicio de la familia y no sustituye el diálogo de padres, madres e hijos; distingan la realidad de la fantasía, tengan sentido crítico cuando eligen dibujos animados; reflexionen acerca de los acontecimientos violentos o degradantes que aparecen: graben programas de calidad para verlos en otro momento; no vean la televisión en la habitación y eviten que la comida familiar se realice frente al televisor.

7. Las escuelas, los padres y las madres deben enseñar a los niños, niñas y adolescentes a observar la televisión y otros medios de comunicación, con un nivel de criticidad tal que permita la reducción de los efectos de la violencia y les ayude a beneficiarse de los aspectos educativos positivos que tanto la televisión y otros medios pretenden transmitir. Es decir, en todos los niveles de desarrollo de los niños, niñas y adolescentes se les debe potenciar las habilidades para que entiendan los medios de comunicación y así proporcionarles un ambiente cultural más sensato y sano.

8. Cuando algún niño o niña se ha comportado de manera inadecuada y se requiere corregir o reprender por lo que ha hecho, es necesario evitar todo tipo de agresión.

9. La comunidad, los centros educativos, la familia y los diferentes medios deben estar concienciados de los programas de prevención y tratamiento que existen acerca de los temas del abuso y la violencia, con el fin de enseñar a los niños, niñas y adolescentes a respetarse y a valorar el potencial que tienen, con el fin de que eviten el enfrentarse a experiencias violentas que les coloque en situaciones de vulnerabilidad y riesgo, las que además de fomentar el desarrollo de los estereotipos, el racismo, la homofobia, y la discriminación, les limita el desarrollo idóneo de sus capacidades psicológicas y mentales.

10. Dado que los medios de comunicación influyen directamente en el desarrollo de los niños, niñas y adolescentes, resulta de importancia identificar la violencia que se difunde a menores de edad, para así reducir los efectos negativos que estos tienen en ellos y ellas.

Las autoras desean reiterar la importancia de proveer a las personas menores de edad de un estilo de vida sano y un ambiente seguro; una adecuada relación con los medios masivos; nunca usar la televisión como su niñera; prestar atención y acompañarles cuando ven algunos programas de televisión, ayudarles a elegir los programas; cambiar el canal y apagar la televisión cuando se presenta algo ofensivo y explicar qué es lo malo de dicho programa; desaprobar los episodios violentos frente a sus hijos e hijas y reforzar la creencia de que tal comportamiento no es la mejor manera de resolver un problema; contrarrestar la presión que ejercen los amigos y compañeros de clase en sus hijos e hijas; comunicarse con otros padres y madres de familia y ponerse de acuerdo para establecer reglas similares sobre la cantidad de tiempo y el tipo 
de programa que pueden ver; motivarlos a ver programas con mensajes que estimulen la cooperación, el cuidado y la ayuda entre personas; estimular la lectura, algún deporte, otras actividades sociales, juegos de mesa, artes plásticas; utilizar los programas, videojuegos o música controversiales para discutir temas acerca de valores familiares, violencia, sexualidad y drogas.

Como mensaje final, las autoras desean hacer una llamada de atención a las personas adultas -responsables de propiciar un óptimo desarrollo integral en las personas menores de edad- acerca de la necesidad de que, en primera instancia, deben aprender a no "Mirar sin ver y escuchar sin oír" (Redondo, párr. 19), para poder enseñar a las generaciones presentes y futuras a utilizar los medios de comunicación de una forma sana, responsable y asertiva; caso contrario, el panorama que se visualiza no es halagador, ya que se continuará perpetuando el uso de los diferentes medios de comunicación de manera autómata, es decir, se continuará mirando sin ver y escuchando sin oír.

\section{Referencias}

Castro, M. y Morales, M. E. (2009). Violencia en diversos ámbitos: Familia, comunidad, centro educativo y medios de comunicación. Heredia, Costa Rica: Programa de Publicaciones de la Universidad Nacional. Instituto de Estudios Interdisciplinarios de la Niñez y la Adolescencia.

Connecticut Clearinghouse A Program of Wheeler Clinic. (s. f.). Los niños y la violencia en la televisión y la influencia de la música y de los videos de música 051408. American Academy of Child and Adolescente Psychiatry (AACAP). Recuperado de https://www.ctclearinghouse. org/topics/customer-files/Los-Ninos-Y-La-Violencia-En-La-Television-y--051408.pdf

Església Bíblica d'Olot. (s. f). Influencia de la música en los adolescentes. Recuperado de http://www. esglesiabiblica.com/index2.php?option=com content\&do pdf=1\&id=77

Familia Nova Schola. (s. f.). La violencia en los medios de comunicación. Efectos en los niños y adolescentes. Centre Londres 94: Psiquiatría, Paidosiquiatría. Recuperado de http:// www.familianova-schola.com/files/Violencia medios comunicacion efectos ninos adolescentes.pdf

Fundación Paniamor. (1998). Manual de contenidos: Violencia y abuso contra personas menores de edad. San José, Costa Rica: Ediciones Proniño.

García, E. P. (2005). Niños, televisión y violencia: Una propuesta de educación para la recepción. Comunicar, 25, 1-14. Recuperado de http://www.redalyc.org/articulo.oa?id=15825186

Huerta, F. (julio-diciembre, 2005). La violencia virtual: Una experiencia de los jóvenes en las videosalas. Estudios Sociales, 13(26), 171-206. Recuperado de http://dialnet.unirioja.es/ servlet/articulo?codigo $=2056872$

Lanza, G. A. (2010). Violencia y medios audiovisuales. El cine y la televisión, ¿son dañinos? Recuperado de http://gustavo-adolfo-lanza-ordonez.suite101.net/violencia-y-mediosaudiovisuales-a7901 
URL: http://www.una.ac.cr/educare

CORREO: educare@una.cr

Leiva, M. (s. f.). Los niños y la violencia en la televisión. Cosas de la infancia. Recuperado de http:// www.cosasdelainfancia.com/biblioteca-compor26.htm

León, A. T. (27 de octubre, 2009). Aspectos psico-sociales de la violencia. Ponencia presentada en el Seminario Violencia en Diversos Ambitos. Heredia. Universidad Nacional.

Levine, M. (1997). La violencia en los medios de comunicación. Cómo afecta al desarrollo de los niños y adolescentes. Bogotá, Colombia: Norma.

Ley general de espectáculos públicos, materiales audiovisuales e impresos Ley no. 7440. (1999). Decreto Ejecutivo N² 26937. Costa Rica.

Organización Panamericana de la Salud y la Organización Mundial de la Salud. (2003). Informe mundial sobre la violencia y la salud. Washington: OPS y OMS.

Ortega R. y Mora-Merchán, J. A. (junio, 1998). Violencia escolar: El problema del maltrato entre iguales. Cuadernos de Pedagogía, 270, 46-50. Recuperado de iescanpeixauet.xeill.net/ mediacio/mediacio/.../maltrato-entre-iguales.../file

Redondo, A. (s. f.a). Los medios de comunicación. Recuperado de http://www.sepeap.org/ imagenes/secciones/Image/ USER /MR sociedad actual medios comunicacion.pdf

Redondo, A. (s. f.b). Papel de la música en los jóvenes. Recuperado de http://www.scptfe.com/ microsites/Congreso AEP 2000/Ponencias-htm/Antonio Redondo.htm

Sánchez, A. (1998). El mundo de la violencia. México: UNAM, Facultad de Filosofía y Letras.

Tisseron, S. (2006). Internet, videojuegos, televisión...: Manual para padres preocupados. Barcelona: Graó.

Tuyaret, M. L. (2009). La violencia en la televisión y su incidencia en los niños y adolescentes. Recuperado de http://www.euskosare.org/komunitateak/ikertzaileak/ehmg/3/txostenak/ Tuyaret

\section{Cómo citar este artículo en APA:}

Castro, M. y Morales, M. E. (2013). Perspectiva de las personas menores de edad acerca de la violencia en los medios de comunicación: videojuegos, televisión y música. Revista Electrónica Educare, 17(3), 229-258. Recuperado de http://www.revistas.una.ac.cr/index.php/EDUCARE/issue/current

Nota: Para citar este artículo en otros sistemas puede consultar el hipervínculo "Como citar el artículo" en la barra derecha de nuestro sitio web:

http://www.revistas.una.ac.cr/index.php/EDUCARE/index 